\title{
PRESSURE DROP IN TWO-PHASE GAS-LIQUID (TAYLOR) FLOW IN MICROREACTORS
}

\author{
Paweł Cygański*, Paweł Sobieszuk, Ryszard Pohorecki \\ Faculty of Chemical and Process Engineering, Warsaw University of Technology, Waryńskiego 1, \\ 00-645 Warsaw, Poland
}

The pressure drop in microreactors for the gas - liquid Taylor flow was measured for 4 different microreactor geometries and 3 different gas - liquid systems. The results have been compared with the existing literature correlations. A selection of the best correlations has been made.

Keywords: gas - liquid Taylor flow, pressure drop, microreactor

\section{INTRODUCTION}

Pressure drop in two-phase gas-liquid flow in pipes and channels has been the subject of research for many decades. Most experimental data existing in the literature have been obtained for a conventional industrial equipment (Dziubiński and Prywer, 2009).

Recently, microreactors and, more generally, microstructures, have become increasingly important parts of modern process equipment. It is important to know, whether the correlations obtained for industrial size channels are applicable to milli- and microchannels. Three approaches to calculate pressure drop values in such channels have been used: the classical approach (Fries et al., 2008), the homogenous model (Kawahara et al., 2002) and the Lockhart-Martinelli (1949) model. Tab. 1 shows the existing information about the pressure drop investigations in micro and milli-channels.

The aim of this paper is to report experimental results obtained for three different systems, and a number of channel geometries and positions (horizontal, vertical). The obtained data have been correlated using the aforementioned three models.

The total pressure drop in gas-liquid microchannels includes four different contributions (Fries et al., 2008):

$$
\Delta P_{T}=\Delta P_{A}+\Delta P_{B}+\Delta P_{G}+\Delta P_{F}
$$

where:

$\Delta P_{A}$ is the pressure drop due to acceleration (Fries et al., 2008):

$$
\Delta P_{A}=G^{2}\left[\left(\frac{x^{2}}{\beta \cdot \rho_{G}}+\frac{(1-x)^{2}}{(1-\beta) \cdot \rho_{L}}\right)_{\text {outlet }}-\left(\frac{x^{2}}{\beta \cdot \rho_{G}}+\frac{(1-x)^{2}}{(1-\beta) \cdot \rho_{L}}\right)_{\text {inlet }}\right]
$$

$\triangle P_{B}$ is the pressure drop over a moving bubble due to a different shape of the bubble front and bubble tail (Bretherton, 1961): 


$$
\Delta P_{B}=3.58 \cdot \frac{\sigma}{r} \cdot \sqrt[3]{9 \cdot C a^{2}}
$$

$\Delta P_{G}$ is the pressure drop due to gravity (Fries et al., 2008):

$$
\frac{\Delta P_{G}}{L}=\left(\beta \cdot \rho_{G}+(1-\beta) \cdot \rho_{L}\right) \cdot g \cdot \sin (\alpha)
$$

$\Delta P_{F}$ is the frictional pressure drop, which can be determined in a number of ways:

- according to the classical approach using the Darcy equation for liquid flow correlated for the fact that only a friction of the channel volume is filled by the liquid:

$$
\frac{\Delta P_{F}}{L}=f \cdot \rho_{L} \cdot u_{T P}^{2} \cdot \frac{2}{d} \cdot \varepsilon_{L}
$$

- according to the homogenous model using the Darcy equation for the two-phase mixture:

$$
\frac{\Delta P_{F}}{L}=f_{H} \cdot \rho_{T P} \cdot u_{T P}^{2} \cdot \frac{2}{d}
$$

\begin{tabular}{|c|c|c|c|c|c|c|c|}
\hline & $\begin{array}{c}\text { Channel cross- } \\
\text { section }\end{array}$ & System & Flow direction & $\begin{array}{c}\text { Dimensions of } \\
\text { main channel } \\
\text { (wide } \mathrm{x} \text { depth } \mathrm{x} \\
\text { length or } \\
\text { diameter } \mathrm{x} \\
\text { length) }[\mathrm{mm}]\end{array}$ & $\begin{array}{c}\text { Hydraulic } \\
\text { diameter } \\
{[\mathrm{mm}]}\end{array}$ & $\begin{array}{c}\text { Channel length } \\
\text { to hydraulic } \\
\text { diameter ratio }\end{array}$ & Model \\
\hline $\begin{array}{c}\text { Bretherton, } \\
1961\end{array}$ & circlular & air and water & horizontal & $5 \times 1000$ & 5 & 200 & classical \\
\hline Chisholm, 1967 & circlular & air and water & $\begin{array}{c}\text { no data } \\
\text { available }\end{array}$ & $\begin{array}{c}\text { no data } \\
\text { available }\end{array}$ & $1 \div 250$ & $\begin{array}{c}\text { no data } \\
\text { available }\end{array}$ & $\begin{array}{l}\text { Lockhart- } \\
\text { Martinelli }\end{array}$ \\
\hline $\begin{array}{l}\text { Mishima and } \\
\text { Hibiki, } 1996\end{array}$ & circlular & air and water & horizontal & $\begin{array}{l}1.05 \times 210 \\
2.05 \times 310 \\
3.12 \times 510 \\
4.08 \times 1000\end{array}$ & $\begin{array}{l}1.05 \\
2.05 \\
3.12 \\
4.08\end{array}$ & $\begin{array}{l}200 \\
151 \\
163 \\
245\end{array}$ & $\begin{array}{l}\text { Lockhart- } \\
\text { Martinelli }\end{array}$ \\
\hline $\begin{array}{l}\text { Lee and Lee, } \\
2001\end{array}$ & rectangular & air and water & vertical & $\begin{array}{c}0.4 \times 20 \times 640 \\
1 \times 20 \times 640 \\
2 \times 20 \times 640 \\
4 \times 20 \times 640\end{array}$ & $\begin{array}{l}0.78 \\
1.91 \\
3.64 \\
6.67\end{array}$ & $\begin{array}{c}499 \\
335 \\
175 \\
95\end{array}$ & $\begin{array}{l}\text { Lockhart- } \\
\text { Martinelli }\end{array}$ \\
\hline $\begin{array}{c}\text { Kawahara et al., } \\
2002\end{array}$ & circlular & air and water & vertical & $0.1 \times 64.5$ & 0.1 & 645 & $\begin{array}{c}\text { homogenous, } \\
\text { Lockhart- } \\
\text { Martinelli }\end{array}$ \\
\hline Yue et al., 2004 & $\begin{array}{l}\text { rectangular } \\
\text { square }\end{array}$ & $\begin{array}{l}\text { nitrogen and } \\
\text { water }\end{array}$ & horizontal & $\begin{array}{c}0.575 \times 0.488 \mathrm{x} \\
34.30 \\
\\
0.333 \times 0.332 \mathrm{x} \\
34.52\end{array}$ & $\begin{array}{l}0.528 \\
0.333\end{array}$ & $\begin{array}{c}65.0 \\
103.7\end{array}$ & $\begin{array}{c}\text { homogenous, } \\
\text { Lockhart- } \\
\text { Martinelli }\end{array}$ \\
\hline $\begin{array}{c}\text { Kreutzer et al., } \\
2005 \mathrm{a}\end{array}$ & circlular & $\begin{array}{c}\text { air and } \\
\text { water/decane/ } \\
\text { tetradecane }\end{array}$ & horizontal & $\begin{array}{c}\text { no data } \\
\text { available }\end{array}$ & 2.3 & $\begin{array}{c}\text { no data } \\
\text { available }\end{array}$ & classical \\
\hline $\begin{array}{l}\text { Saisorn and } \\
\text { Wongwises, } \\
2010\end{array}$ & circlular & air and water & vertical & $\begin{array}{c}0.15 \times 104 \\
0.22 \times 120 \\
0.53 \times 320\end{array}$ & $\begin{array}{l}0.15 \\
0.22 \\
0.53\end{array}$ & $\begin{array}{l}693 \\
545 \\
603\end{array}$ & $\begin{array}{l}\text { Lockhart- } \\
\text { Martinelli }\end{array}$ \\
\hline $\begin{array}{l}\text { The present } \\
\text { paper }\end{array}$ & circlular square & $\begin{array}{c}\text { nitrogen and } \\
\text { water/ethanol/ } \\
\text { heptane }\end{array}$ & $\begin{array}{l}\text { vertical and } \\
\text { horizontal }\end{array}$ & $\begin{array}{l}0.15 \times 25 \\
0.4 \times 1000\end{array}$ & $0.15 ; 0.4$ & $\begin{array}{l}166 \\
250\end{array}$ & $\begin{array}{c}\text { classical, } \\
\text { homogenous, } \\
\text { Lockhart- } \\
\text { Martinelli }\end{array}$ \\
\hline
\end{tabular}

- according to the Lockhart-Martinelli model, as discussed in the following section.

Table 1. Pressure drop investigations in micro and milli-channels 
The pressure drop contributions defined by Eqs. (2-4) are simple to calculate from the experimental conditions.

It should be pointed out that all traditional models (classical, homogenous and Lockhart-Martinelli) are based on the assumptions which in the case of the Taylor flow are rather unrealistic. A more rational approach has been suggested by Kreutzer and co-workers (2005a, 2005b, 2005c) and Abiev (2011). However, their approach requires the knowledge of slug length, which renders it less practical from the engineering point of view. For this reason we limited our analysis to the traditional models.

\subsection{The classical model (Fries et al., 2008)}

In this model the Darcy Equation (5) is used, with the physicochemical properties $\left(\rho_{\mathrm{L}}\right.$ and $\left.\mu_{\mathrm{L}}\right)$ of the liquid, and two-phase superficial velocity $u_{T P}$. The friction factor $\mathrm{f}$ is given by Equations (7-9).

Standard correlation:

$$
f=\frac{16}{\operatorname{Re}}
$$

Bretherton (1961):

$$
f=\frac{16}{\operatorname{Re}}\left[1+0.465 \cdot \frac{d_{H}}{L_{L}} \cdot\left(\frac{1}{C a}\right)^{\frac{1}{3}}\right]
$$

Kreutzer et al. (2005a):

$$
f=\frac{16}{\operatorname{Re}}\left[1+0.17 \cdot \frac{d_{H}}{L_{L}} \cdot\left(\frac{\mathrm{Re}}{C a}\right)^{\frac{1}{3}}\right]
$$

\subsection{The homogenous model (Kawahara et al., 2002)}

The homogeneous model assumes that the two phases (gas and liquid) form a homogenous mixture. The pressure drop is calculated on the basis of one-phase flow formulas with the appropriate two-phase mixture parameters values. Although this assumption is rather far from the physical reality of the Taylor flow, we decided to check the applicability of this model for the sake of completeness of the analysis.

The literature describes many correlations for the viscosity and density of gas-liquid mixture determination. In this paper the following correlations are discussed:

- density:

Kawahara et al., (2002):

$$
\frac{1}{\rho_{H}}=\frac{x}{\rho_{G}}+\frac{1-x}{\rho_{L}}
$$

- viscosity:

Owens (1961):

$$
\mu_{T P}=\mu_{L}
$$

Dukler et al., (1964):

$$
\mu_{T P}=\varepsilon_{G} \cdot \mu_{G}+\left(1-\varepsilon_{G}\right) \cdot \mu_{L}
$$

Beattie and Walley (1982): $\quad \mu_{T P}=\left(1-\varepsilon_{G}\right) \cdot \mu_{L} \cdot\left(1+2.5 \varepsilon_{G}\right)+\varepsilon_{G} \cdot \mu_{G}$

Using the calculated values of density and viscosity of the gas-liquid mixture, the frictional pressure drop can be calculated from the Darcy equation in the form given in Eq. (6).

The frictional factor is determined from the correlation (14): 


$$
f_{H}=\frac{16}{\operatorname{Re}_{H}}
$$

\subsection{The Lockhart and Martinelli model}

Lockhart and Martinelli (1949) proposed that the pressure drop in two-phase flow can be related to the equivalent pressure drop in one-phase flow by two-phase parameter $\Phi$ :

$$
\left(\frac{\Delta P_{F}}{L}\right)_{T P}=\phi_{L}^{2} \cdot\left(\frac{\Delta P_{F}}{L}\right)_{L}=\phi_{G}^{2} \cdot\left(\frac{\Delta P_{F}}{L}\right)_{G}
$$

where $\Phi_{L}$ is correlated as (Chisholm, 1967):

$$
\phi_{L}^{2}=1+\frac{C}{X}+\frac{1}{X^{2}}
$$

and $\mathrm{X}$ is the ratio:

$$
X^{2}=\frac{\left(\frac{\Delta P_{F}}{L}\right)_{L}}{\left(\frac{\Delta P_{F}}{L}\right)_{G}}
$$

The pressure drop for the gas phase and the liquid phase is calculated separately using the Darcy equation for one phase (18) and the standard definition of the friction factor $f$, using Eq. (7).

$$
\frac{\Delta P_{F}}{L}=f \cdot \rho \cdot u^{2} \cdot \frac{2}{d}
$$

The main problem in applying the Lockhart-Martinelli model is to determine the $C$ factor. Table 2 shows the existing $C$ factor correlations for laminar gas-liquid flows.

Table 2. $C$ factor correlations

\begin{tabular}{|l|l|c|}
\hline & \multicolumn{1}{|c|}{ C correlation } & $\begin{array}{c}\text { Eq. } \\
\text { number }\end{array}$ \\
\hline Chisholm (1967) & $C=5$ & $(19)$ \\
\hline Mishima and Hibiki (1996) & $C=21 \cdot\left[1-e^{(-319 \cdot d)}\right]$ & $(20)$ \\
\hline \multirow{2}{*}{ Lee and Lee (2001) } & $C=6.833 \cdot 10^{-8} \cdot \lambda^{-1.317} \cdot \mathrm{Re}_{L}^{0.557} \cdot C a^{0.719}$ & \\
\hline Saisorn and Wongwises (2010) & $\lambda=\frac{\mu_{L}^{2}}{\rho_{L} \sigma d}$ & $(21)$ \\
\hline
\end{tabular}

In this work we used our experimental data to find a new $C$ correlation. We also investigated the contribution of inlet effects to the pressure drop in microreactors.

\section{EXPERIMENTAL SYSTEM}

Two kinds of microreactors were used: a microreactor built of polydimethyloxosilane (PDMS) and another one, built of glass. In order to eliminate inlet and outlet effects, the inlet/outlet systems, without 
the main channel, were also prepared. For each set of experimental conditions the pressure drop was measured twice: for the whole microreactor, and for the inlet system only. It allows to calculate pressure drop in microchannel alone .

The glass microreactor has a circular cross-section, $0.4 \mathrm{~mm}$ in diameter and $100 \mathrm{~mm}$ of the main channel's length. Fig. 1 shows the glass microreactor.

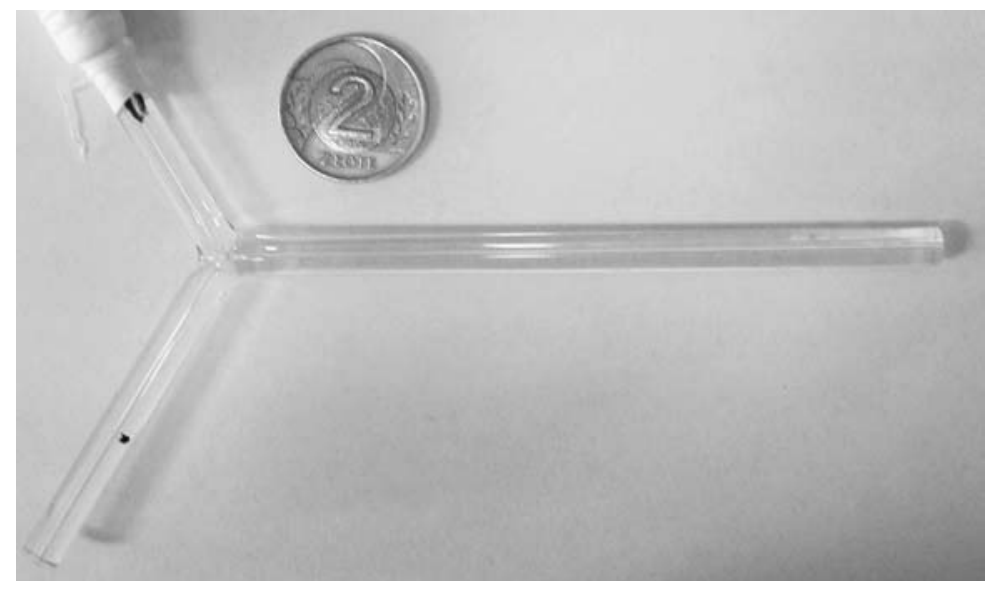

Fig. 1. Glass microreactor

The PDMS microreactors have a square cross-section, $0.15 \mathrm{~mm}$ wide and the main channel $25 \mathrm{~mm}$ in length. A PDMS microreactor with a Y-shaped inlet is shown in Fig. 2a), a PDMS microreactor with a T-shape inlet is shown in Fig. 2b), and a PDMS microreactor with a T1-shaped inlet is shown in Fig. 2c).

a)

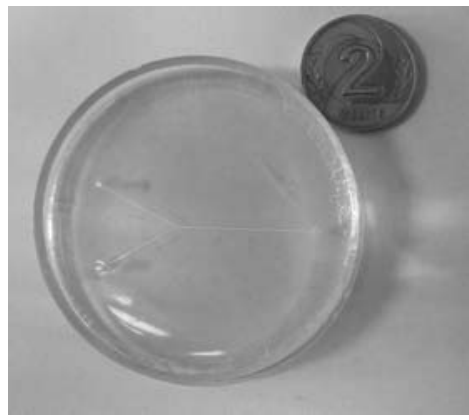

b)

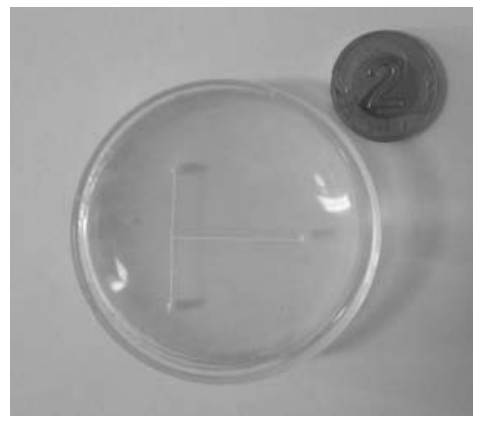

c)

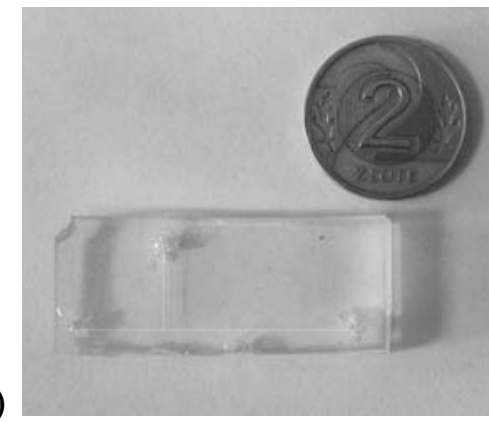

Fig. 2. PDMS microreactors photo: a) Y-shape, b) T-shape, c) T1-shape

In the T-shape microreactor the main channel is perpendicular to both inlet channels, in the T1-shape one of inlet channels is perpendicular to the main channel, while the other lies on its axis. The T1-shape microreactor was used in two different configurations (Fig. 3a) 3b)), T-shape arrangement is shown in Fig. 3c).

The experimental set-up is shown in Fig. 4. Gas (nitrogen) was supplied from a cylinder (1) through a reducing valve and a gas flow regulator (2) (mass flow meter and controller: Brooks Smart Series, type $5850 \mathrm{~S})$. Gas pressure was measured using manometer (5). The liquid was supplied by a syringe pump (3). At the outlet of the microreactor (4) the atmospheric pressure was maintained. In the experiments three liquids were used (water, ethanol and heptane). 
a)

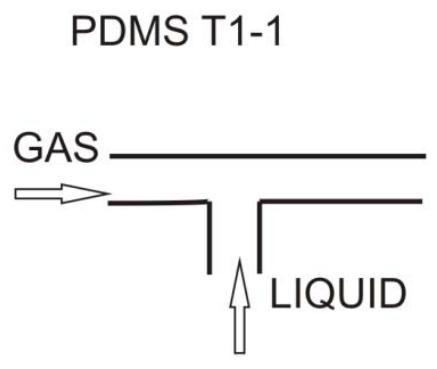

b) PDMS T1-2

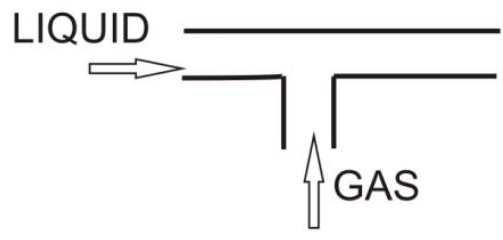

c) PDMS T

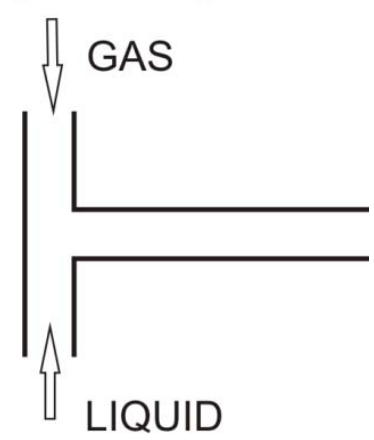

Fig. 3. Scheme of the gas and liquid inlets in PDMS microreactors:

a) PDMS T1-shape, liquid in perpendicular channel (denoted as PDMS T1-1), b) PDMS T1-shape, gas in perpendicular channel (denoted as PDMS T1-2), c) PDMS T-shape

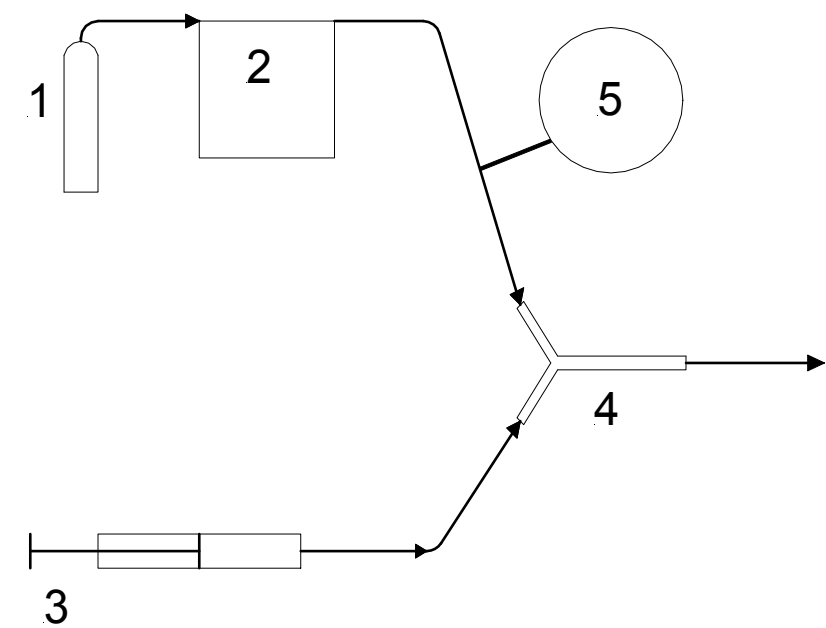

Fig. 4. The experimental set-up:

1-gas cylinder, 2-gas flow regulator, 3-syringe pump, 4-microreactor or inlet system, 5-manometer

\section{RESULTS AND DISCUSSION}

\subsection{Influence of microreactor position on pressure drop}

The aim of this part of the experiment was to check whether the position (horizontal or vertical) of the main channel had any influence (other than hydrostatic pressure) on the overall pressure drop. It was supposed that this position may influence the process of bubble/slug formation and/or the character of the liquid flow around the bubble.

The pressure drop was measured for two positions of microreactors: with main microchannel oriented horizontally or vertically. Fig. 5 shows the overall pressure drop $\Delta P_{\Sigma}$ in glass microreactor in systems nitrogen-heptane and nitrogen-water for vertical and horizontal positions.

We also measured the overall pressure drop $\Delta P_{\Sigma}$ in two position (horizontal and vertical) in PDMS-T and PDMS-T1 microreactors in nitrogen-ethanol system (see Fig. 6). 


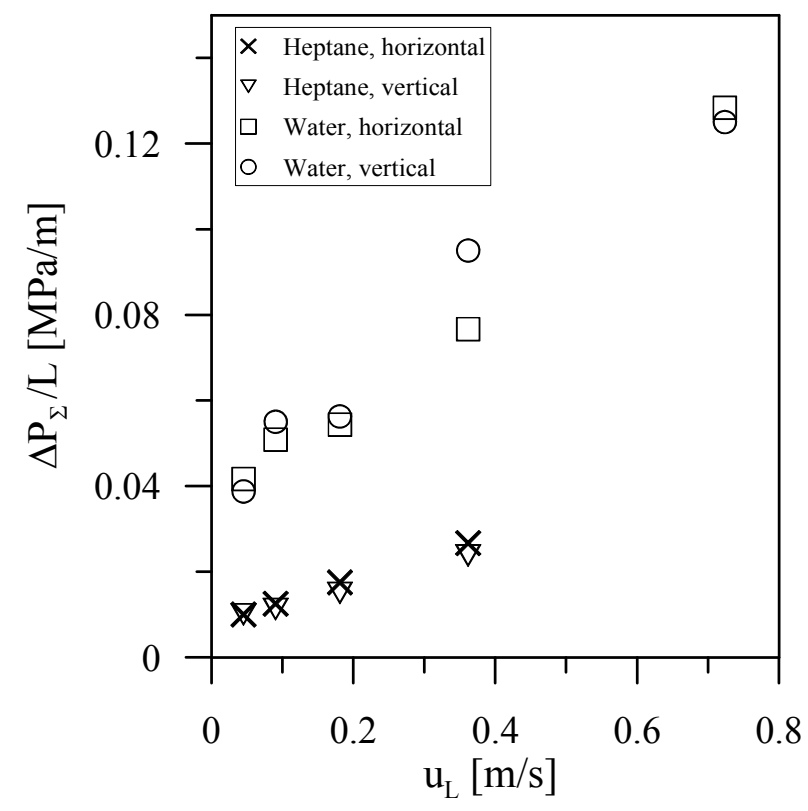

Fig. 5. The influence of microreactor (glass) position on overall pressure drop $\left(u_{G}=0.1 \mathrm{~m} / \mathrm{s}\right)$

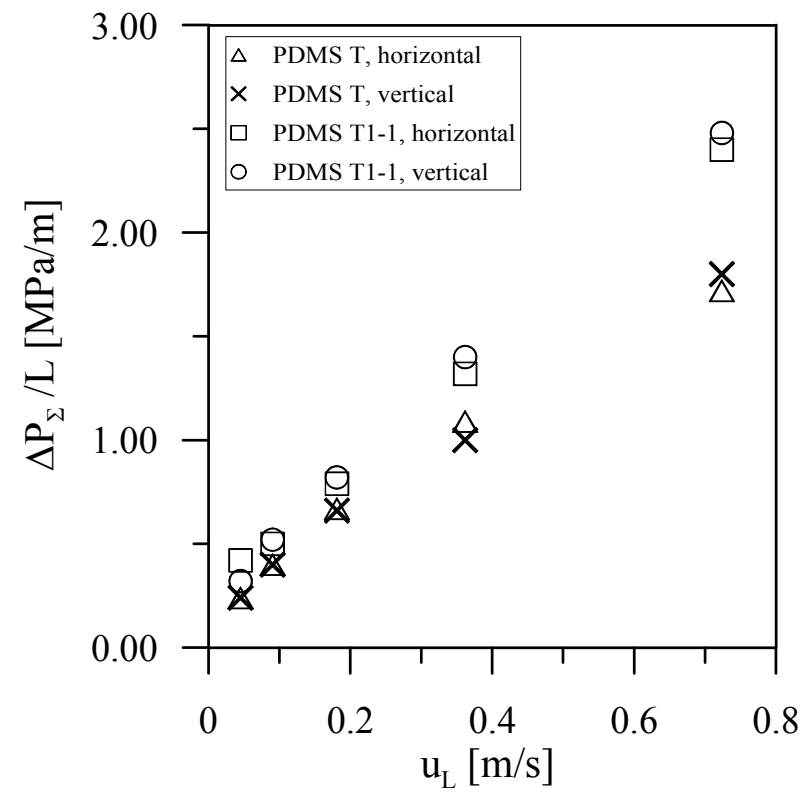

Fig. 6. The influence of microreactor (PDMS) position on overall gradient pressure drop $\left(u_{G}=0.7 \mathrm{~m} / \mathrm{s}\right)$

As can be seen, for lower values of liquid velocity the overall influence of microreactor position on the pressure drop is not significant (the channel is quite short, so the hydrostatic component, Eq. (4), is not important). For higher velocity values the influence of microchannels position on overall pressure drop is not higher than $10 \%$. In further considerations only horizontal microreactors were discussed.

\subsection{Inlet effects}

Fig. 7 shows the results, obtained using the glass microreactor. Ethanol, water and heptane were used to measure pressure drop in this microreactor and in the inlet system. Fig. 8 shows the experimental data for ethanol-nitrogen system for PDMD T and PDMS T1-1 microreactors and the inlet systems. 


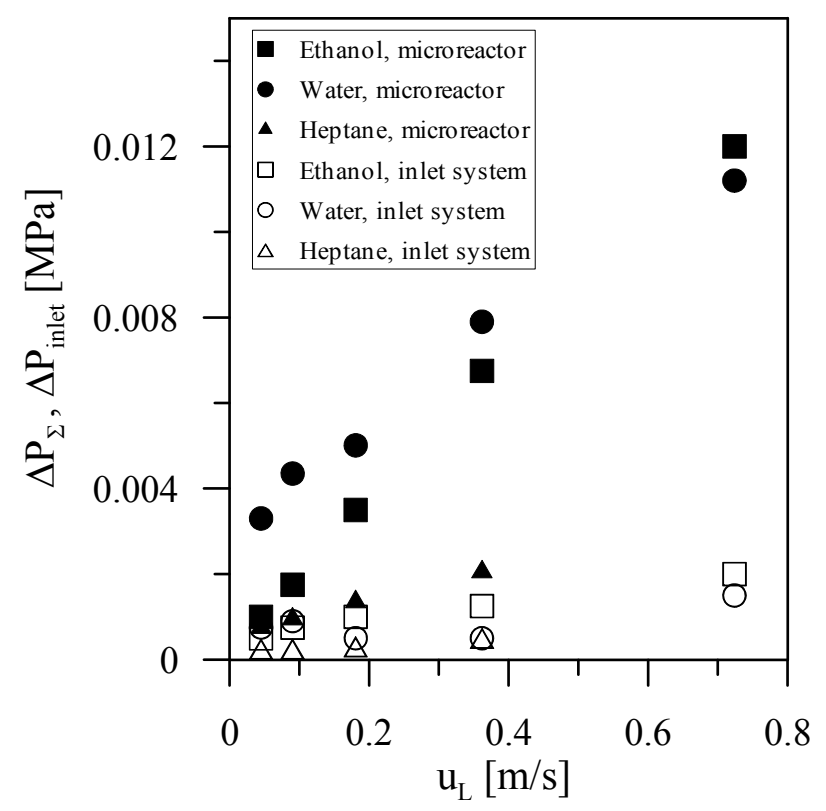

Fig. 7. Comparison of the pressure drop in the microreactor and the inlet system (glass microreactor, ethanol, water, heptane). Superficial gas velocity is constant $\left(u_{G}=0.1 \mathrm{~m} / \mathrm{s}\right)$

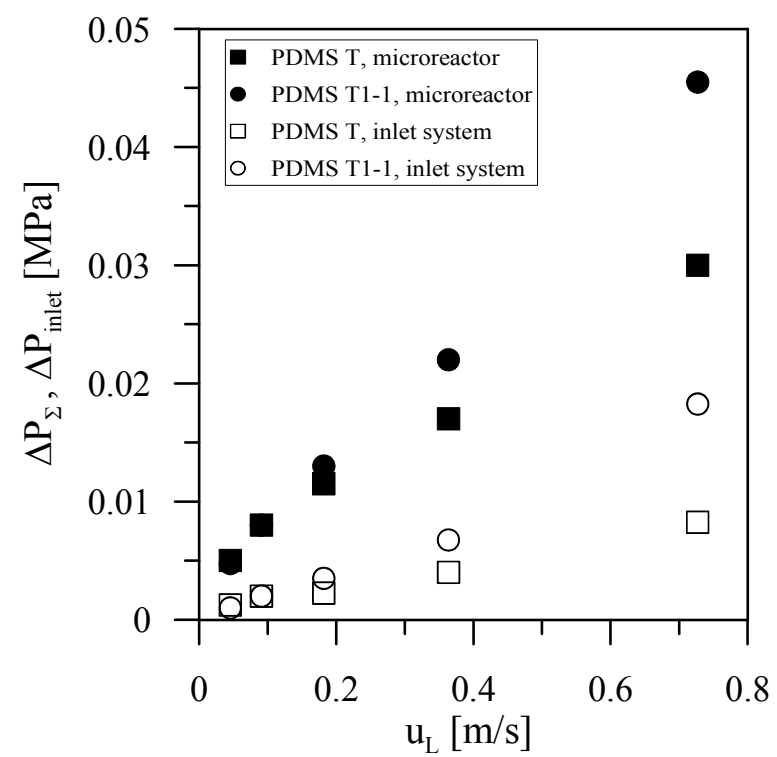

Fig. 8. Comparison of the pressure drop in microreactors and inlet systems (PDMS T and PDMS T1-1, ethanol). Superficial gas velocity is constant $\left(u_{G}=0.1 \mathrm{~m} / \mathrm{s}\right)$

As can be seen the contribution of the inlet pressure drop in the microreactors was in the range: $10 \% \div 40 \%$ of the total measured pressure drop. It is therefore essential to distinguish between the two contributions: that of the inlet system and that of the main channel. Naturally, for longer main channels, the inlet contribution becomes less important.

\subsection{Microchannel pressure drop}

According to Eq. (1) the total pressure drop in gas-liquid flow in a microchannel is composed of four parts. The frictional pressure drop constitutes the main contribution in all our data. Fig. 9 shows results for the glass microreactor, Fig. 10 shows results for the PDMS microreactor. 
a)

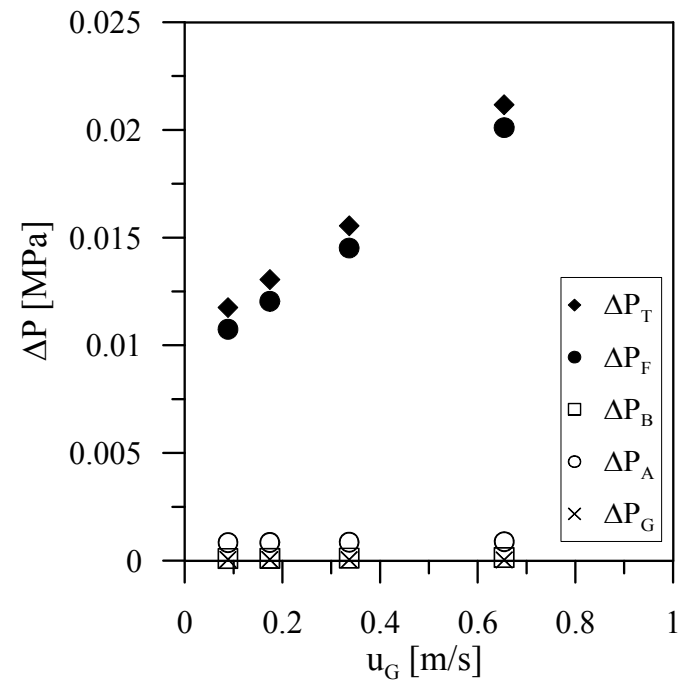

b)

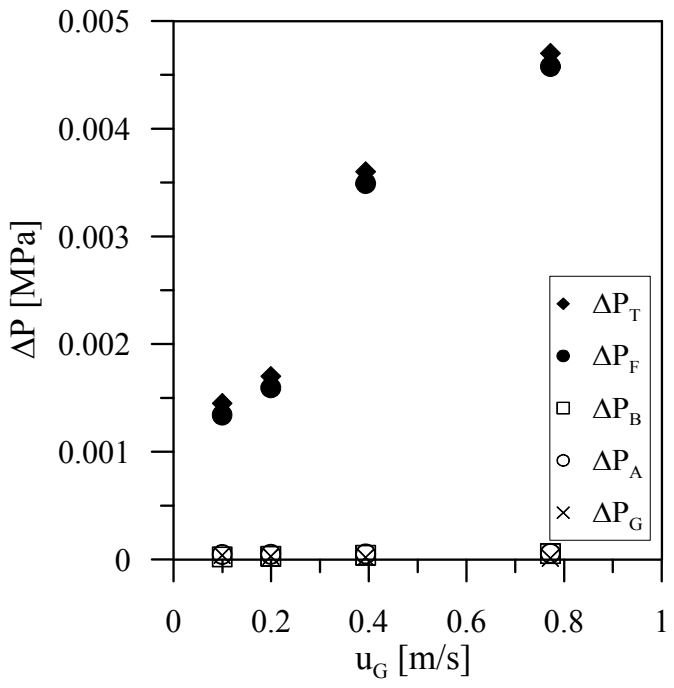

c)

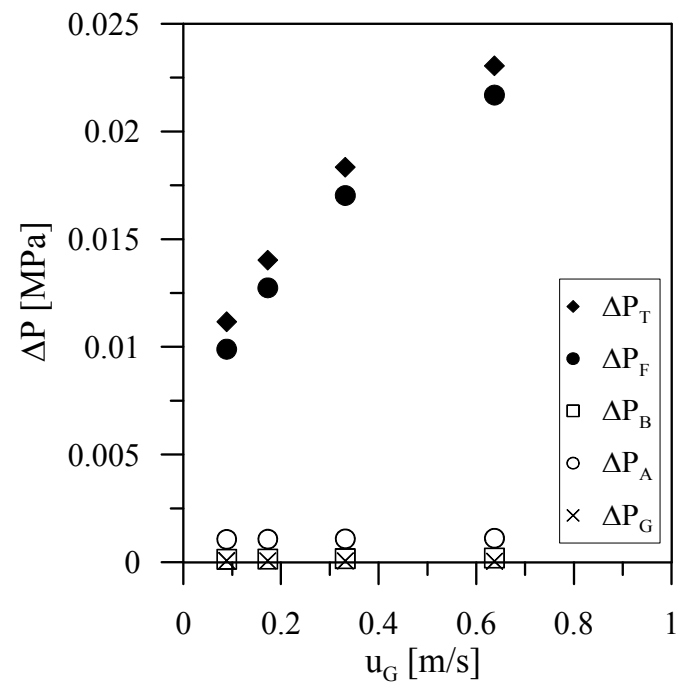

Fig. 9. Contributions to the total pressure drop in the glass microchannel: a) ethanol, $\left.u_{L}=0.73 \mathrm{~m} / \mathrm{s}, \mathrm{b}\right)$ heptane, $\left.u_{L}=0.18 \mathrm{~m} / \mathrm{s}, \mathrm{c}\right)$ water, $u_{L}=0.73 \mathrm{~m} / \mathrm{s}$

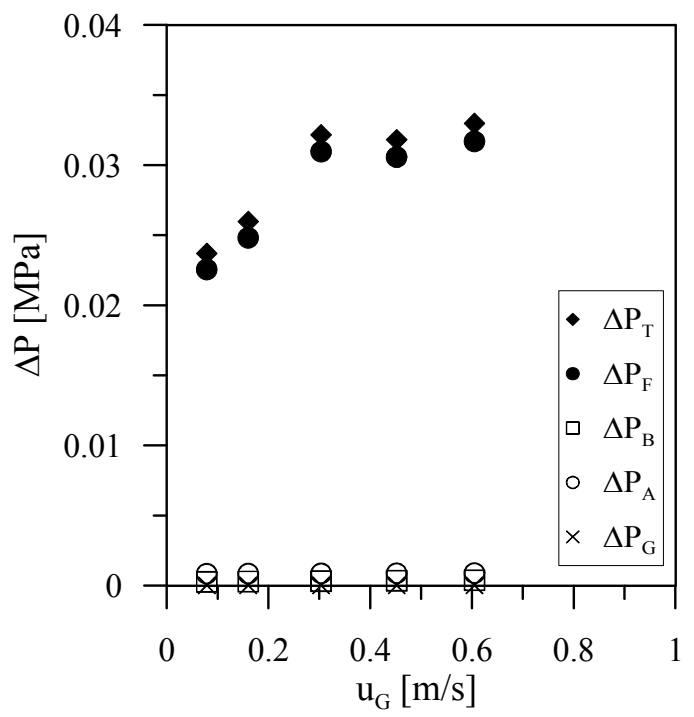

Fig. 10. Contribution to the total pressure drops in the PDMS microchannel for ethanol, and $u_{L}=0.73 \mathrm{~m} / \mathrm{s}$ 
As can be seen the total pressure drop in the microchannel is practically equal to the frictional pressure drop. Our experimental data have been compared with all the three models discussed earlier.

\subsection{The classical model}

For the classical model a comparison of the experimental data with those calculated from Eq. (5) using three correlations for the factor $\mathrm{f}$ Eqs. (7-9) has been made. A comparison of the calculated frictional pressure drop values with the experimental data is shown in Fig. 11. For a quantitative comparison the standard deviation values were calculated as:

$$
\sigma_{S}=\frac{\sum_{i-1}^{N} \sqrt{\left(\left(\frac{\Delta P_{F}}{L}\right)_{i(\text { experimental })}-\left(\frac{\Delta P_{F}}{L}\right)_{i(\text { correlation })}\right)^{2}}}{N}
$$

a)

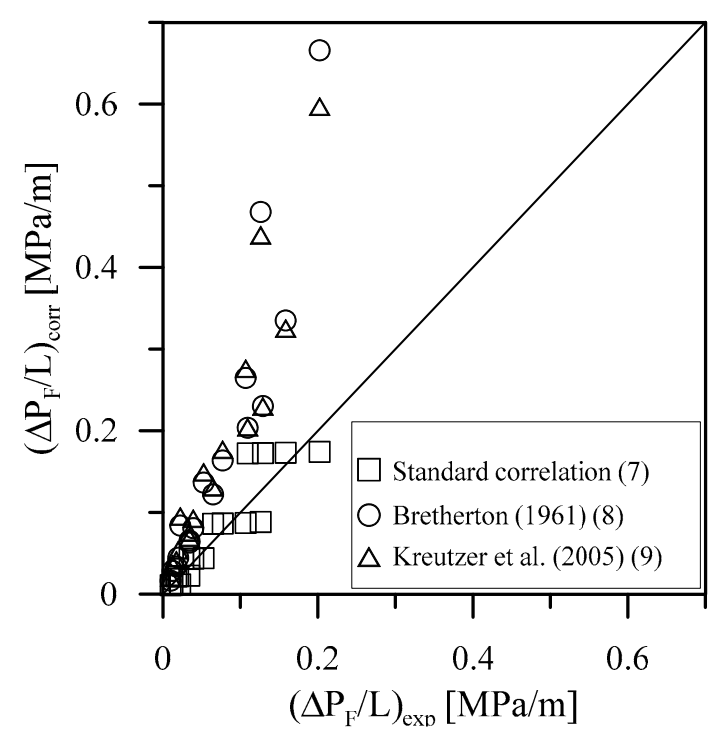

c)

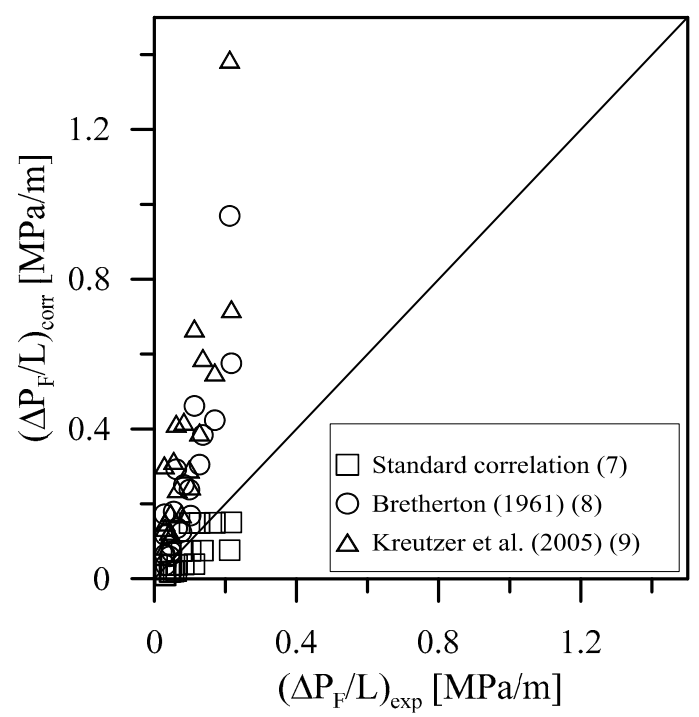

b)

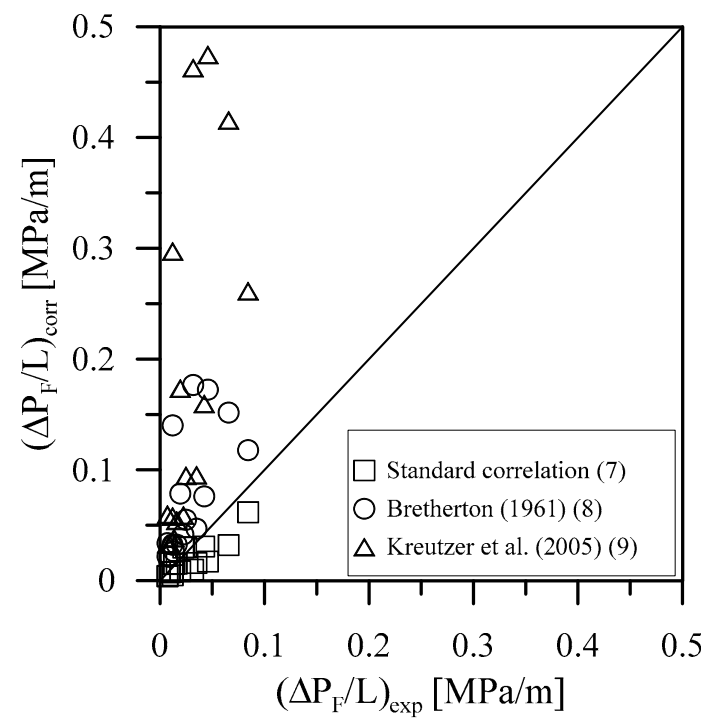

d)

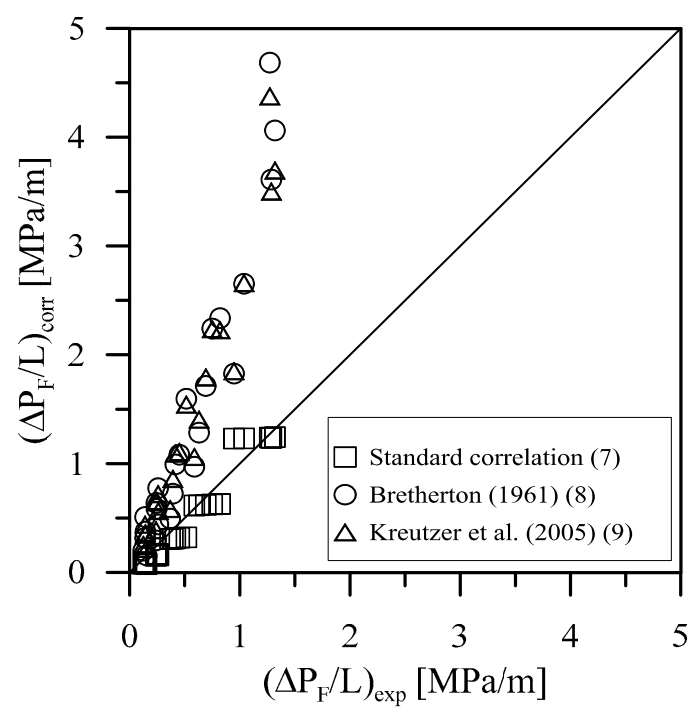

Fig. 11. Comparison of the experimental data with the existing correlations (7-9) for the frictional coefficient: a) glass microreactor, water-nitrogen; b) glass microreactor, heptane-nitrogen system; c) glass microreactor, water nitrogen; d) PDMS microreactor, ethanol-nitrogen 
The calculated values of the standard deviation are shown in Table 3

Table 3. The values of standard deviation for the considered frictional coefficient correlations in the classical $\operatorname{model}(\mathrm{MPa} / \mathrm{m})$

\begin{tabular}{|l|c|c|c|}
\hline \multirow{2}{*}{ system $\downarrow$} & \multicolumn{3}{|c|}{ Classical model } \\
\cline { 2 - 4 } & $\begin{array}{c}\text { Bretherton (1961), } \\
\text { Eqs. (5, 8) }\end{array}$ & $\begin{array}{c}\text { Standard correlation, } \\
\text { Eqs. (5, 7) }\end{array}$ & $\begin{array}{c}\text { Kreutzer et al. (2005a), } \\
\text { Eqs. (5, 9) }\end{array}$ \\
\hline $\begin{array}{l}\text { Glass } \\
\text { Ethanol-nitrogen }\end{array}$ & 0.157 & 0.023 & 0.147 \\
\hline $\begin{array}{l}\text { Glass } \\
\text { Heptane-nitrogen }\end{array}$ & 0.073 & 0.016 & 0.106 \\
\hline $\begin{array}{l}\text { Glass } \\
\text { Water-nitrogen }\end{array}$ & 0.231 & 0.048 & 0.382 \\
\hline $\begin{array}{l}\text { PDMS } \\
\text { Ethanol-nitrogen }\end{array}$ & 1.196 & 0.112 & 1.150 \\
\hline Average & 0.414 & 0.049 & 0.446 \\
\hline
\end{tabular}

It is seen, that the classic model with the standard correlation for $\mathrm{f}$ (Eqs. 5, 7) gives a relatively better agreement than the Bretherton (Eq. 8) and the Kreutzer (Eq. 9) correlations. The standard deviation values are in the range from 0.016 to $0.112 \mathrm{MPa} / \mathrm{m}$. It should be pointed out that in the case of Bretherton and Kreutzer correlations very large deviations are observed for higher values of pressure drop.

\subsection{The homogeneous model}

For the homogeneous model, the selection of methods for calculating density and viscosity of a homogenous mixture is the most important thing. In this paper, density was calculated from Eq. (10). To select the correlation for viscosity, which would give the best agreement with the experimental data, viscosity was calculated from Eqs. (11-13). The friction coefficient was calculated using Eq. (14) and the frictional pressure drop was calculated using Eq.(6). The calculated values of the frictional pressure drop were then compared with the experimental values. Table 4 shows standard deviation values for the ethanol-nitrogen system in the glass microreactor.

Table 4. The values of standard deviation for the considered viscosity correlations in the homogenous model $(\mathrm{MPa} / \mathrm{m})$ for ethanol-nitrogen system in the glass microreactor

\begin{tabular}{|c|c|c|c|}
\hline$\mu \rightarrow$ & $\begin{array}{c}\text { Owens (1961) } \\
\text { Eq. (11) }\end{array}$ & $\begin{array}{c}\text { Dukler et al. (1964) } \\
\text { Eq. (12) }\end{array}$ & $\begin{array}{c}\text { Beattie and Whalley } \\
(1982) \\
\text { Eq. (13) }\end{array}$ \\
\hline Homogenous model & 0.074 & 0.024 & 0.087 \\
\hline
\end{tabular}

As can be seen, the best results are obtained using Dukler's (1964) correlation for $\mu$. Similar results were obtained for other physico-chemical systems and microreactors. In the further considerations the frictional coefficient was therefore calculated using Dukler's correlation for viscosity. For density the Kawahara correlation (Eq. 10) is used as mentioned earlier. The values of standard deviations are shown in Table 5. 
It is seen that the homogenous model Eqs. $(6,14)$ gives similar results as the classical model with the standard correlation for $f$ (Eqs. 5, 7). For density and viscosity the formulas of Kawahara (Eq. 10) and Dukler (Eq. 12) should be used.

Table 5. The values of standard deviation for the considered frictional coefficient correlations in the homogenous $\operatorname{model}(\mathrm{MPa} / \mathrm{m})$

\begin{tabular}{|l|c|}
\hline \multicolumn{1}{|c|}{ system } & $\begin{array}{c}\text { Homogenous } \\
\text { model } \\
\text { Eqs. }(6,14)\end{array}$ \\
\hline $\begin{array}{l}\text { Glass } \\
\text { Ethanol-nitrogen }\end{array}$ & 0.024 \\
\hline $\begin{array}{l}\text { Glass } \\
\text { Heptane-nitrogen }\end{array}$ & 0.017 \\
\hline $\begin{array}{l}\text { Glass } \\
\text { Water-nitrogen }\end{array}$ & 0.047 \\
\hline $\begin{array}{l}\text { PDMS } \\
\text { Ethanol-nitrogen }\end{array}$ & 0.111 \\
\hline Average & 0.050 \\
\hline
\end{tabular}

a)

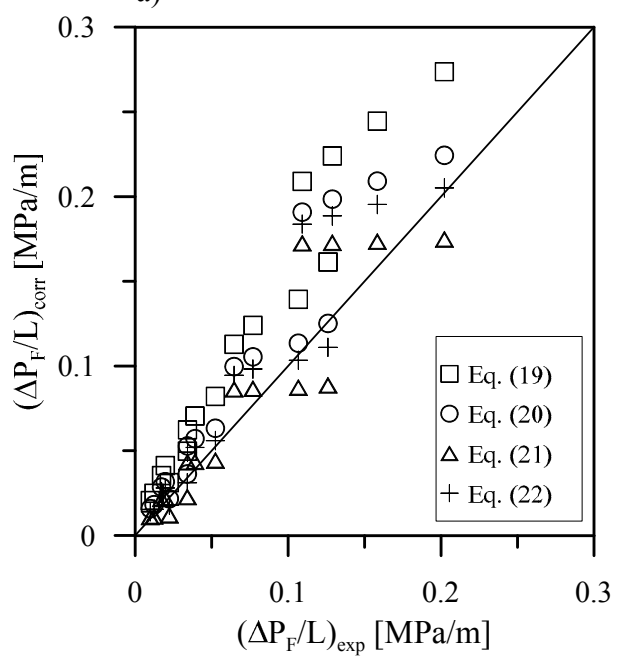

b)

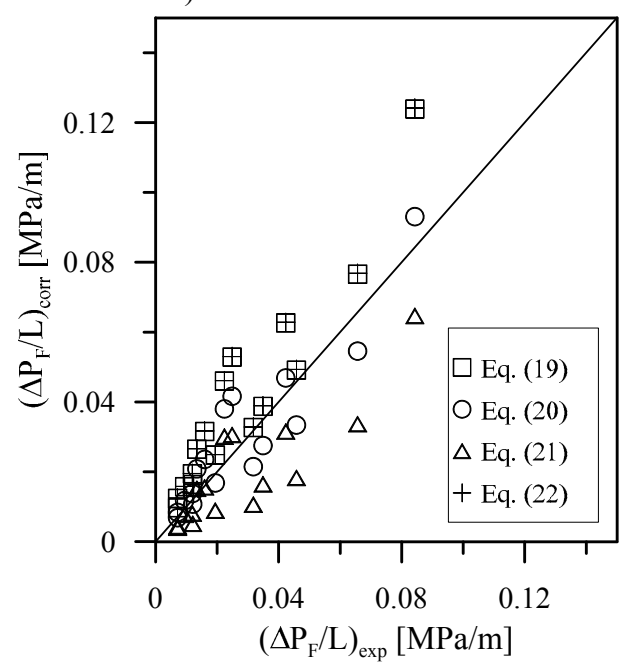

c)

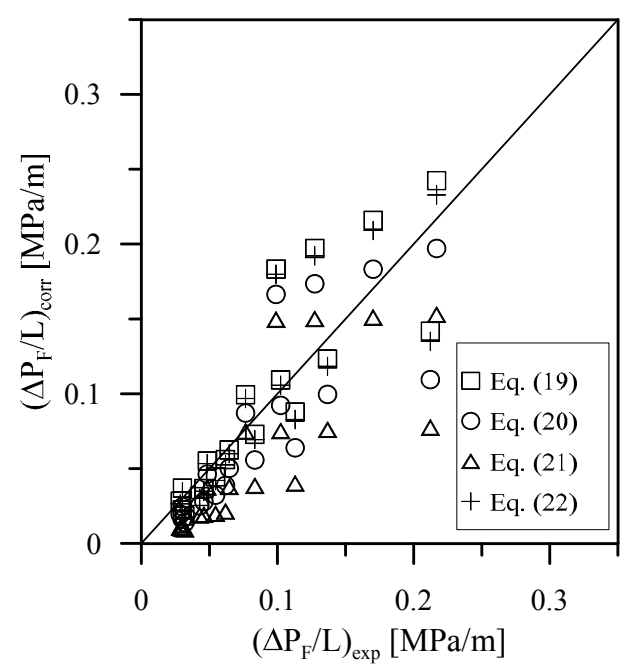

Fig. 12. Comparison of the experimental data with the existing correlations (Eqs. 19-22) for the frictional pressure drop in the glass microchannel: a) ethanol, b) heptane, c)water. Standard correlation (Eq. 7) was used for $f$ 


\subsection{The Lockhart-Martinelli model}

The experimental data have been compared with those calculated using the Lockhart-Martinelli model together with the existing correlations for the factor $f$ (Eq. 7) and the factor $C$ Eqs. (19-22). Fig. 12 shows the parity plots for the glass microchannel, Fig. 13 shows the parity plot for the PDMS microchannel (in all three PDMS microreactors the main microchannels were identical).

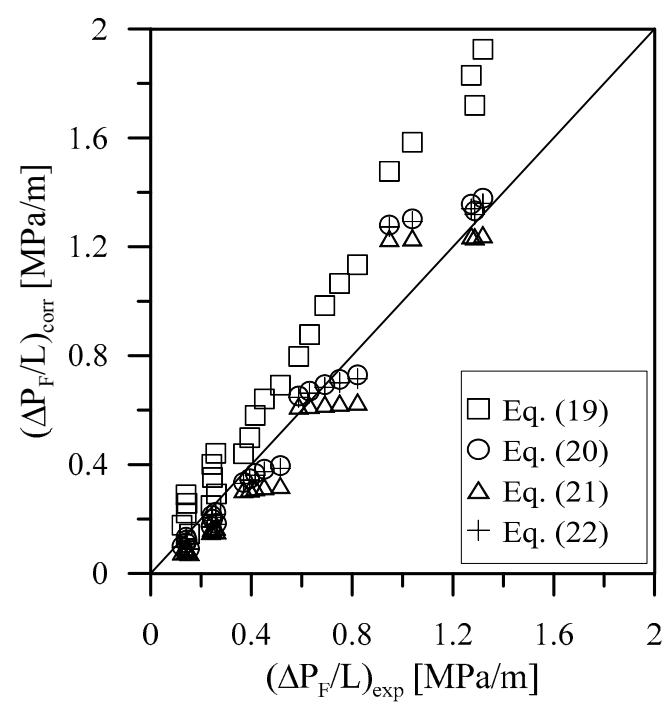

Fig. 13. Comparison of the experimental data with the existing correlations (Eqs. 19-22) for the frictional pressure drop in the PDMS microchannel for ethanol. Standard correlation (Eq. 7) was used for $f$

A comparison of our experimental data with those calculated from the Lockhart-Martinelli model using the existing correlations shows a generally reasonable agreement, except for the Chisholm (1967) correlation. This is understandable, as this correlation was developed for bigger channel diameters. Tab. 6 shows the values of the standard deviation for the data shown in Figs. 12-13 (Lockhart Martinelli model). The results are somewhat better than those obtained for the classical model using standard (Eq. 7) correlation for the f coefficient, but the difference is not as large as it might have been expected (taking into account the assumptions of the classical model, rather far from reality for Taylor flow).

Table 6. The values of standard deviation for the different correlations for coefficient $C$ in Lockhart-Martinelli $\operatorname{model}(\mathrm{MPa} / \mathrm{m})$

\begin{tabular}{|c|c|c|c|c|}
\hline system $\downarrow$ & Chisholm (1967) & $\begin{array}{c}\text { Mishima and } \\
\text { Hibiki (1996) }\end{array}$ & $\begin{array}{c}\text { Lee and Lee } \\
(2001)\end{array}$ & $\begin{array}{c}\text { Saisorn and } \\
\text { Wongwises } \\
(2010)\end{array}$ \\
\hline $\begin{array}{c}\text { Glass } \\
\text { Ethanol }\end{array}$ & 0.042 & 0.027 & 0.028 & 0.022 \\
\hline $\begin{array}{c}\text { Glass } \\
\text { Heptane }\end{array}$ & 0.043 & 0.028 & 0.012 & 0.015 \\
\hline $\begin{array}{c}\text { Glass } \\
\text { Water }\end{array}$ & 0.036 & 0.034 & 0.042 & 0.032 \\
\hline $\begin{array}{c}\text { PDMS } \\
\text { ethanol }\end{array}$ & 0.280 & 0.098 & 0.101 & 0.098 \\
\hline Average & 0.100 & 0.047 & 0.046 & 0.0432 \\
\hline
\end{tabular}


On the basis of our experimental data we proposed our own correlations for the $C$ factor:

$$
C=0.71 \cdot \lambda^{-0.233} \cdot C a^{-0.024}
$$

and for the friction factor:

$$
f=\frac{14.015}{\operatorname{Re}^{1.054}}
$$

The parity plot of the results obtained for all the microchannels and all the systems using this correlation is shown in Fig. 14.

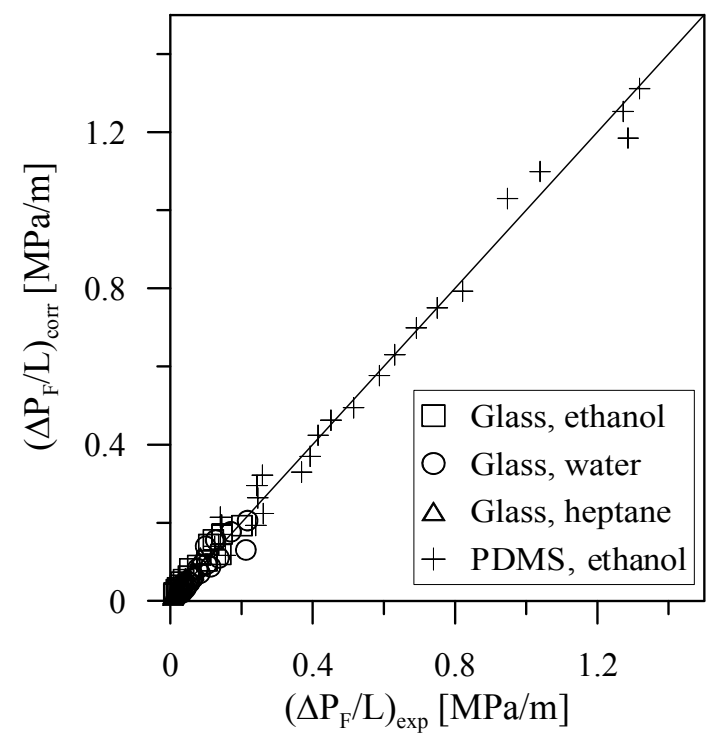

Fig. 14. Parity plot for the Lockhart-Martinelli model with own correlations for $C$ and $f$ (Eqs. 24-25)

The standard deviation for all the experimental points is $0.025 \mathrm{MPa} / \mathrm{m}$, which shows a good fit of the proposed correlations to the experimental results.

\section{CONCLUSIONS}

The pressure drop in the Taylor gas-liquid flow in microchannels was measured. Four different microreactors and four different liquids were used. A 10 - 40\% contribution of the inlet pressure drop to the total microreactor pressure drop was observed. Having eliminated the inlet effect, the pressure drop in the microchannel was determined. The experimental results were compared with the classical, homogenous and the Lockhart-Martinelli models. For each model a selection of correlations used was made.

For the classical model the best agreement with the experiments was obtained using the standard correlation (Eq. 7) for the friction coefficient $\mathrm{f}$.

For the homogenous model; comparable results were obtained using the correlation (14) for $f$ and the formulas of Kawahara (Eq. 10) and of Dukler (Eq. 12) for the density and viscosity of the mixture.

For the Lockhart-Martinelli model the best agreement was obtained using the standard (Eq. 7) correlation for the friction coefficient $\mathrm{f}$, and the Saisorn and Wongwises correlation (Eq. 22) for the $C$ factor. 
Generally, the Lockhart-Martinelli model gave the best agreement with the experiment, but differences between the described models was not large, provided properly selected correlations for the model parameters were used. Our own correlations for the Lockhart-Martinelli model parameters were also proposed.

This work was supported by the budget sources for The National Centre for Science (Poland), Grant No. N N209026140.

\section{SYMBOLS}

$C$

$C a=\mu_{L} u_{T P} \sigma$

$C a_{H}=\mu_{T P} u_{T P} \sigma$

$d$

$f$

g

G

$L$

$N$

$\Delta P_{\Sigma}$

$\triangle P_{A}$

$\triangle P_{B}$

$\Delta P_{F}$

$\Delta P_{G}$

$\Delta P_{\text {inlet }}$

$\Delta P_{T}$

$\operatorname{Re}=u d \rho / \mu$

$\operatorname{Re}_{H}=u_{T P} d \rho_{T P} / \mu_{T P}$

$u$

$V_{b}$

$V_{s}$

$x$

$X$

Greek symbols

$\alpha$

$\beta=V_{b} /\left(V_{S}+V_{b}\right)^{-1}$

$\varepsilon_{G}=u_{G} u_{T P}{ }^{-1}$

$\lambda=\mu_{L}^{2} \rho_{L}^{-1} \cdot \sigma^{-1} \cdot d_{h}^{-1}$

$\phi$

$\rho$

$\mu$

$\sigma$

\section{Subscript}

\section{G}

H

$L$

TP factor in the Lockhart-Martinelli model, -

capillary number, -

capillary number, -

hydraulic diameter, $\mathrm{m}$

friction factor, -

gravity acceleration, $\mathrm{m} \cdot \mathrm{s}^{-2}$

total (gas and liquid) mass flux, $\mathrm{kg} \cdot \mathrm{s}^{-1} \cdot \mathrm{m}^{-2}$

microchannel length, $\mathrm{m}$

number of experiments, -

overall measured pressure drop (inlet and total pressure drop), $\mathrm{MPa}$

pressure drop due to acceleration, MPa

pressure drop over a moving bubble due to the change in shape between the bubble

front and bubble tail, MPa

frictional pressure drop, $\mathrm{MPa}$

pressure drop due to gravity, MPa

inlet measured pressure drop, MPa

total pressure drop in microchannel, $\mathrm{MPa}$

Reynolds number,-

Reynolds number,-

superficial velocity, $\mathrm{m} \cdot \mathrm{s}^{-1}$

volume of the bubbles in microchannel, $\mathrm{m}^{3}$

volume of the liquid slugs in microchannel, $\mathrm{m}^{3}$

gas mass fraction, -

Lockhart-Martinelli parameter,-

channel slope angle, deg

gas hold-up relative to phases volume,-

gas hold-up,-

parameter, -

two-phase multiplier in the Lockhart-Martinelli model,-

density, $\mathrm{kg} \cdot \mathrm{m}^{-3}$

viscosity, Pa.s

surface tension, $\mathrm{N} \cdot \mathrm{m}^{-1}$

gas

homogenous model

liquid

two phase 


\section{REFERENCES}

Abiev R.Sh., 2011. Modeling pf pressure losses for the slug flow of gas-liquid mixture in mili- and microchannels. Theor. Found. Chem. Eng., 45, 156-163. DOI: 10.1134/S0040579511020011.

Bretherton F.P., 1961. The motion of long bubbles in tubes. J. Fluid Mech., 10, 166-188. DOI: $10.1017 / \mathrm{S} 0022112061000160$.

Beattie D.R.H., Whalley P.B., 1982. A simple two-phase flow frictional pressure drop calculation method. Int. J. Multiph. Flow, 8, 83-87. DOI: 10.1016/0301-9322(82)90009-X.

Chisholm D., 1967. A theoretical basis for the Lockhart-Martinelli correlation for two-phase flow. Int. J. Heat Mass Transfer., 10, 1767-1778. DOI: 10.1016/0017-9310(67)90047-6.

Dukler A.E., Wicks III M., Cleveland R.G., 1964. Frictional pressure drop in two-phase flow: A. A comparison of existing correlations for pressure loss and holdup. AIChE J., 10, 38-43. DOI: 10.1002/aic.690100117.

Dziubiński M., Prywer J., 2009. Mechanics of two phase fluids. WNT, Warsaw, 417-462 (in Polish).

Fries D.M., Trachsel F., von Rohr P.R., 2008. Segmented gas-liquid flow characterization in rectangular microchannels. Int. J. Multiph. Flow, 34, 1108-1118. DOI: 10.1016/j.ijmultiphaseflow.2008.07.002.

Kawahara A., Chung P.M.-Y., Kawaji M., 2002. Investigation of two-phase flow pattern, void fraction and pressure drop in a microchannel. Int. J. Multiph. Flow, 28, 1411-1435. DOI: 10.1016/S0301-9322(02)00037-X.

Kreutzer M.T., van der Eijnden M.G., Kapteijn F., Moulijn J.A., Heiszwolf J.J., 2005a. The pressure drop experiments to determine slug lengths in multiphase monoliths. Catal. Today, 105, 667-672. DOI: 10.1016/j.cattod.2005.06.007.

Kreutzer M. T., Kapteijn F., Moulijn J. A., Kleijn C. R., Heiszwolf J. J., 2005b. Inertial and interfacial effects on pressure drop of Taylor flow in capillaries. AIChE J., 51, 2428-2440. DOI: 10.1002/aic.10495.

Kreutzer M.T., Kapteijn F., Moulijn J.A., Heiszwolf J.J., 2005c. Multiphase monolith reactors: Chemical reaction engineering of segmented flow in microchannels. Chem. Eng. Sci., 60, 5895-5916. DOI: 10.1016/j.ces.2005.03.022.

Lee H.J., Lee S.Y., 2001. Pressure drop correlations for two-phase flow within horizontal rectangular channels with small heights. Int. J. Multiph. Flow, 27, 783-796. DOI: 10.1016/S0301-9322(00)00050-1.

Lockhart R., Martinelli R., 1949. Proposed correlations of data for isothermal two-phase, two-component flow in pipes. Chem. Eng. Progr., 45, 39-48.

Mishima K., Hibiki T., 1996. Some characteristics of air-water two-phase flow in small diameter vertical tubes. Int. J. Multiph. Flow, 22, 703-712. DOI: 10.1016/0301-9322(96)00010-9.

Owens W.L., 1961. Two-phase pressure gradient. Int. Development in Heat Transfer, Pt II. ASME, New York.

Saisorn S., Wongwises S., 2010. The effects of channel diameter on flow pattern, void fraction and pressure drop of two-phase air-water flow in circular micro-channels. Exp. Therm. Fluid. Sci., 34, 454-462. DOI: 10.1016/j.expthermflusci.2009.02.006.

Yue J., Chen G., Yuan Q., 2004. Pressure drops of single and two-phase flows through T-type microchannel mixers. Chem. Eng. J., 102, 11-24. DOI: 10.1016/j.cej.2004.02.001.

Received 23 February 2012

Received in revised form 02 August 2012

Accepted 05 August 2012 